\title{
REVIEW
}

\section{Pulmonary hypertension in systemic sclerosis and systemic lupus} erythematosus

\author{
S.R. Johnson*,\# and J.T. Granton*,9
}

ABSTRACT: Pulmonary arterial hypertension (PAH) is a severe manifestation of systemic sclerosis (SSc) and systemic lupus erythematosus (SLE). Due to improvements in the understanding of the pathogenesis of these diseases, improved methodological rigour in the conduct of epidemiological studies and the advent of successful therapies, our understanding of SSc-PAH and SLE-PAH has evolved considerably. In this review we will review the current evidence regarding the prevalence, prognostic factors and survival estimates for SSc-PAH and SLE-PAH. In doing so, we will compare and contrast these two diseases, highlight clinically useful features, discuss methodological limitations of existing data, and draw attention to areas where research is needed.

KEYWORDS: Lupus, pulmonary hypertension, scleroderma, systemic lupus erythematosus, systemic sclerosis

ulmonary arterial hypertension $(\mathrm{PAH})$ is a severe manifestation of many of the seropositive connective tissue diseases (CTDs). It has long been recognised as a manifestation of systemic sclerosis (SSc) and systemic lupus erythematosus (SLE) [1, 2]; however, it can occur in other connective tissue diseases, including SSc-SLE overlap syndrome [3], mixed connective tissue disease (MCTD) [4-6], inflammatory myositides (dermatomyositis and polymyositis) [7, 8], Sjögren's syndrome [9] and rheumatoid arthritis [10]. In patients suspected of having PAH, Doppler echocardiography has been recommended to detect pulmonary hypertension $(\mathrm{PH})$ and evaluate for left ventricular systolic and diastolic dysfunction, leftsided ventricular enlargement or valvular heart disease [11]. Right heart catheterisation is required to confirm the presence of PAH, establish a specific diagnosis and determine the severity of PAH [11]. Using catheterisation derived haemodynamics, $\mathrm{PAH}$ is defined as a mean pulmonary artery pressure $\left(\bar{P}_{\mathrm{pa}}\right) \geqslant 25 \mathrm{mmHg}$ and a pulmonary capillary wedge pressure of $\leqslant 15 \mathrm{mmHg}$ [12].

Of the CTDs associated with PAH, SSc-PAH and SLE-PAH are the most common [13]. Typically, these patients are grouped together in studies of PAH-specific therapies under the category of CTD $[14,15]$. Together, advances in our knowledge of the mechanism of SSc-PAH and SLE-PAH, improved methodological rigour in the conduct of SSc-PAH and SLE-PAH observational studies, and the introduction of successful PAH specific therapies have resulted in a progressive evolution in our understanding of SSc-PAH and SLE-PAH. It has been suggested that SSc-PAH and SLE-PAH are heterogeneous diseases with variable responses to therapy. As such, categorisation of these patients together may not be appropriate and may affect the outcome of studies [16].

The most frequently observed and reported aetiology of $\mathrm{PH}$ in SSc is $\mathrm{PAH}$. However, $\mathrm{PH}$ in SSc can be the result of a number of other aetiologies, such as pulmonary veno-occlusive disease (PVOD) [17], left ventricular systolic and diastolic dysfunction (heart failure with preserved ejection fraction) [18], and pulmonary fibrosis [19]. DORFMULLER et al. [20] demonstrated the frequent presence of PVOD-like pathologic changes in the veins and pre-septal venules of the pulmonary vasculature of SSc-PAH patients. These other aetiologies probably play a role in the differing response to therapy and prognosis of SSc-PH compared to SLE-PH and idiopathic PAH [21].

In this review we will synthesise the current knowledge of the prevalence, prognostic factors and
AFFILIATIONS

*Division of Rheumatology, Dept of Medicine, University Health Network, Mount Sinai Hospital and University of Toronto,

\#University Health Network

Pulmonary Hypertension Programme, University Health Network, and "Divisions of Respirology and Critical Care Medicine, Dept of Medicine, University Health Network and University of Toronto, Toronto, ON, Canada.

CORRESPONDENCE

S.R. Johnson

Division of Rheumatology, Ground

Floor, East Wing

Toronto Western Hospital

399 Bathurst Street

Toronto

ON

M5T 2S8

Canada

E-mail: Sindhu.Johnson@uhn.on.ca

Received:

April 192011

Accepted after revision:

May 022011

PROVENANCE

Submitted article, peer reviewed. 
survival estimates for SSc-PAH and SLE-PAH. In doing so, we will compare and contrast the two diseases, highlight clinically useful features, discuss methodological limitations of existing data, and draw attention to areas where research is needed.

\section{SCLERODERMA-ASSOCIATED PAH}

$\mathrm{SSc}$ is an autoimmune disease characterised by immune activation leading to inflammation, fibrosis and vasculopathy. It is currently hypothesised that, in a genetically susceptible individual, exposure to an environmental stimulus results in immune activation and release of immune mediators. Transforming growth factor (TGF)- $\beta$ stimulates fibroblast proliferation, leading to increased collagenase and collagen synthesis, resulting in the fibrotic manifestations of SSc [22]. Fibroblast stimulation also results in increased vascular endothelial growth factor, which leads to aberrant neoangiogenesis. In the setting of SSc lung disease, macrophage activation leads to increased production of TGF- $\beta$, tumour necrosis factor- $\alpha$, platelet-derived growth factor and fibronectin, resulting in the radiographic and clinical features of lung fibrosis and nonspecific inflammatory pneumonia. Advanced pulmonary vasculopathy histologically appears as smooth muscle hypertrophy, adventitial and intimal proliferation, in situ thrombosis and/or plexiform lesion(s). Together, these vascular changes result in a low-flow, high-resistance vessel and produce the clinical manifestations of PAH.

Although common in the setting of SSc, the vasculopathic manifestations can vary across individual patients [23]. Vasculopathy of the small blood vessels can present as telangiectasia. Telangiectasias are composed of vasodilated venules without evidence of neovascularisation or inflammation [24]. They not only occur externally on the skin, but also on the tongue, buccal mucosa, oesophageal lumen and stomach. The pathogenesis of telangiectasia has largely been studied in the setting of hereditary haemorrhagic telangiectasia (HHT). Patients with HHT demonstrate genetic mutations in the TGF- $\beta$ receptor complex, most notably endoglin (a TGF- $\beta$ binding protein) and activin receptor-like kinase 1 . Telangiectasias are more frequently found in SSc patients with elevated soluble endoglin, and pulmonary artery pressure $(\mathrm{Ppa})$ is positively correlated with elevated endoglin levels [25]. It is hypothesised that the presence of telangiectasia is an expression of an aberrant vascular process. It may reflect an attempt to increase blood perfusion to hypoxic tissues that is a result of the loss of normal circulation in the affected tissue [26].

The presence of telangiectasia in SSc patients should prompt a few considerations. First, it has been suggested that increased numbers of telangiectasias may be a marker for PAH. Using a 0 to 2 scoring system ( 0 : none; $1:<10 ;$ and $2: \geqslant 10$ telangiectasias) to evaluate the presence of matted telangiectasia in 11 body areas, a 10-point increase in telangiectasia score has an adjusted odds ratio of PAH by right heart catheterisation of 12.4 (95\% CI 1.78-85.9; $p=0.01$ ) [26]. A second consideration is that the luminal telangiectasia can be friable, and put these patients at increased risk of gastrointestinal bleeding [27]. In its most severe form, it can result in gastric antral vascular ectasia (GAVE or "watermelon stomach"). We have reported a case of GAVE unmasked by the use of prostaglandin E1 (alprostadil) resulting in upper gastrointestinal bleeding necessitating blood transfusion [28]. The presence of luminal telangiectasias and GAVE may be relevant if one is contemplating anticoagulation of patients with SSc-PAH. Vasculopathy of the small cutaneous vessels can also be observed in the nail folds. Indeed, the presence of abnormal nail fold capillaries manifesting as enlarged capillaries or "drop out" of capillaries can be a useful diagnostic clue to the presence of an underlying connective tissue disease in the aetiology of PAH. Evaluation of abnormal nail fold capillaries can be easily undertaken in the clinic by visual inspection of the nail fold, or with the use of capillaroscopy.

Vasculopathy of the medium sized vessels can present as Raynaud's phenomenon: cold or stress induced, triphasic discoloration of any acral region of the body (fingers, nose, penis, toes or ears). Persistently decreased perfusion can lead to digital pulp loss, pitting, digital shortening, ulceration or gangrene. Raynaud's phenomenon is a sensitive criterion in the diagnosis of SSc occurring in $>90 \%$ of SSc patients. As such, it can be useful in the evaluation of SSc-PAH; if absent, the diagnosis of SSc is unlikely. However, Raynaud's phenomenon is not a specific finding as it can occur in other CTDs (SLE, MCTD and inflammatory myositides) and idiopathic PAH. When recruiting a PAH patient with Raynaud's phenomenon for participation in a clinical trial, and when SSc is the suspected underlying diagnosis, classification criteria should be used to ensure that a better defined cohort of SSc patients are classified as SSc [29]. The widely used SSc classification criteria [29] has been criticised [30,31], and should not be used as diagnostic criteria [32]. Revised classification criteria for the recruitment of SSc patients into clinical trials are currently being developed through a joint initiative between the European League Against Rheumatism and the American College of Rheumatology [33].

With improved methodological rigour and the availability of PAH specific therapies, our understanding of the epidemiology of PAH has evolved over the past four decades. Early echocardiographic-based prevalence estimates were as high as $43-59 \%[34,35]$, but more recent estimates range between $21 \%$ and $26.7 \%[36,37]$. More rigorous right heart catheterisationbased prevalence estimates are lower and range between $7 \%$ and $29 \%$, with the majority of estimates at the lower end (table 1) [34, 38-41]. Prevalence estimates vary substantially due to variability in patient selection (academic/community practice, disease subtype, symptomatic/nonsymptomatic and presence/absence of other issues such as interstitial lung disease), method (echocardiogram or cardiac catheterisation) and threshold of pulmonary pressures used for diagnosis. It has been argued that studies may underestimate the true prevalence since clinically severe or symptomatic patients are referred to academic centres [46].

Classically, it was believed that PAH occurred later in the disease course of SSc, and occurred more frequently in patients with the limited subtype of SSc. However, these notions are being challenged. In a retrospective cohort of $78 \mathrm{SSc}-\mathrm{PAH}$ patients, 55\% had a PAH diagnosis within 5 yrs of the first nonRaynaud's phenomenon symptom. Furthermore, there was no difference in the frequency of early onset PAH between SSc patients with the limited or diffuse subtypes [47]. AvOUAC et al. [45] have refined classical thinking by proposing that there are two subsets of SSc patients who are at risk of developing PH: 1) patients with the limited subtype, in the late stage of the disease with a diffusing capacity of the lung for carbon monoxide per unit of alveolar volume ( $\mathrm{L} \mathrm{L}, \mathrm{CO} / \mathrm{VA})$ are at risk of $\mathrm{PAH}$; and 2$)$ 
TABLE 1 Prevalence of systemic sclerosis-associated pulmonary arterial hypertension

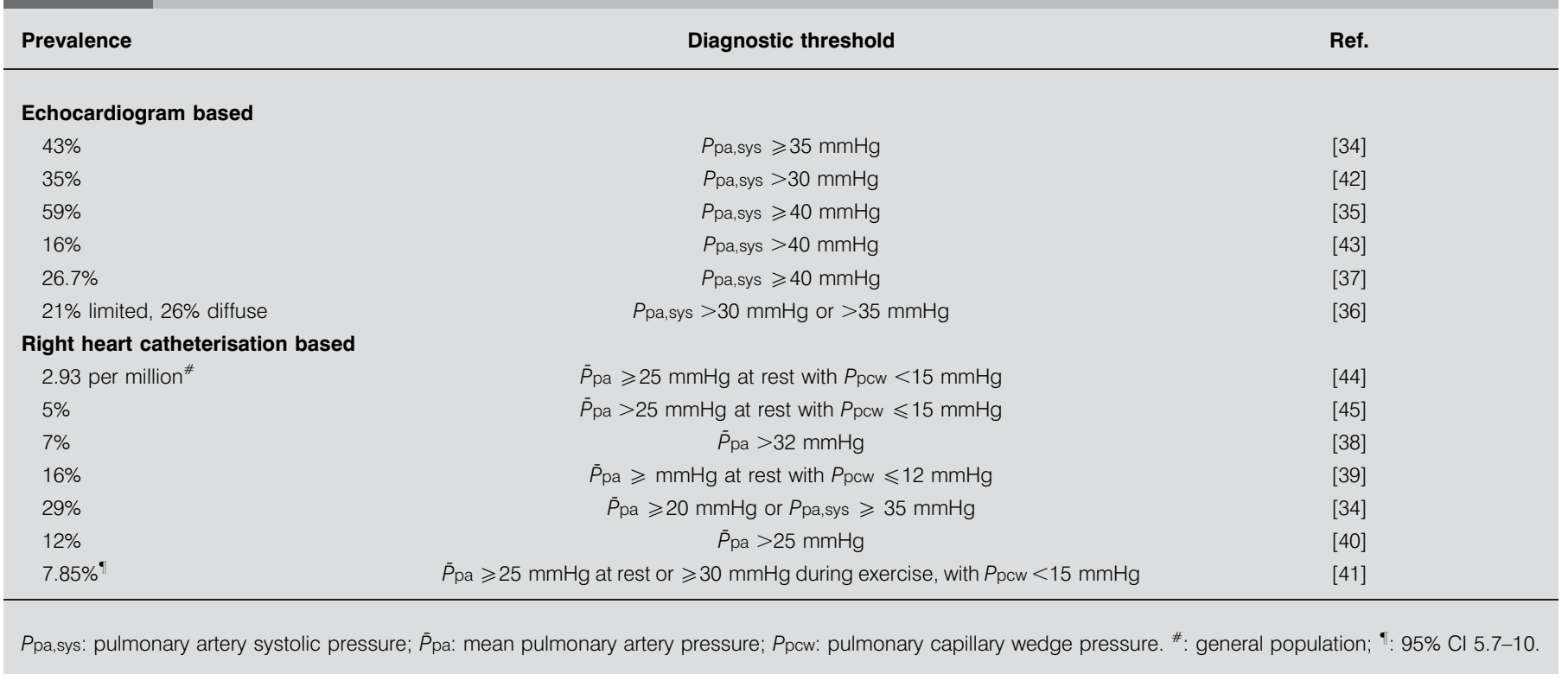

males with the diffuse subtype and a decreased $D \mathrm{~L}, \mathrm{CO} / V \mathrm{~A}$ are at risk of $\mathrm{PH}$ secondary to interstitial lung disease.

$\mathrm{PAH}$ is a leading cause of death in SSc patients [48]. Early survival estimates published in 1996 reported a median survival of 12 months, and 1-, 2-, 3- and 5-yr survival of 50, 44, 40 and $4 \%$, respectively [49]. However, survival estimates have improved over time. Using data from the same centre in 2011, $1-, 2-$ and 3-yr survival have improved to 81,72 and $64 \%$, respectively, with a median survival of 4.9 yrs [50]. Other groups have also independently demonstrated a gradual improvement in survival over time (table 2) [44, 51]. The improvement in survival may be due to the availability of $\mathrm{PAH}$ specific therapies, namely prostaglandins [58], endothelin receptor antagonists [59] and phosphodiesterase-5 inhibitors [60]. Alternately, heightened awareness of PAH complicating SSc may have led to earlier referral for evaluation and treatment. This could result in lead-time and length-time biases, thereby affecting the interpretation of survival rates. Despite the progressive improvement in survival, the longterm $(>5 \mathrm{yr})$ survival remains poor. Patients with SSc continue to do worse than their other PAH counterparts. In the REVEAL registry (Registry to EValuate Early And Long-term PAH disease management), SSc was independently associated with worse prognosis [61].

We conducted a systematic review of prognostic factors for survival in PAH in patients with SSc [62]. Human leukocyte antigen (HLA) DRw6 [63], HLA DRw52 [63], elevated mean right atrial pressure [40], higher mixed venous oxygen saturation [44], peripheral vascular resistance [40, 55, 56], stroke volume index [55], pulmonary artery capacitance [55], age [44, 64], sex $[44,64]$, functional class $[44,55,56]$, estimated glomerular filtration rate $<60 \mathrm{~mL}$ per min per $1.73 \mathrm{~m}^{-2}$ and signs of right

\section{TABLE 2 Survival in systemic sclerosis-associated pulmonary arterial hypertension}

Survival \%

\begin{tabular}{|c|c|c|c|c|c|}
\hline $1-y r$ & $2-y r$ & $3-y r$ & $5-y r$ & Median & \\
\hline Not reported & 60 & Not reported & Not reported & Not reported & [52] \\
\hline 50 & 44 & 40 & 4 & 12 months & [49] \\
\hline Not reported & 50 & Not reported & 10 & Not reported & [53] \\
\hline 81 & 63 & 56 & Not reported & 3 yrs & [40] \\
\hline 81 & 71 & NR & Not reported & Not reported & [54] \\
\hline 78 & 58 & 47 & Not reported & Not reported & [44] \\
\hline 86 & 68 & 56 & Not reported & Not reported & [51] \\
\hline 85 & 72 & 67 & 36 & 4 yrs & [55] \\
\hline 80 & 56 & 51 & Not reported & Not reported & {$[56]$} \\
\hline 82 & Not reported & Not reported & Not reported & Not reported & [57] \\
\hline 81 & 72 & 64 & 49 & $4.9 \mathrm{yrs}$ & [58] \\
\hline Not reported & 72 & Not reported & 48 & Not reported & [16] \\
\hline
\end{tabular}


heart failure [56] are reported predictors of survival (table 3). In patients with $\mathrm{SSc}-\mathrm{PH}$ and interstitial lung disease, a lower $\mathrm{DL}, \mathrm{CO}$ (HR 0.95, 95\% CI 0.92-0.98) and presence of pericardial effusion (HR 3.96, 95\% CI 1.56-10.06) were associated with survival [65]. Many of these findings are comparable to prognostic factors for survival in idiopathic PAH [66]. The presence of anti-centromere $[44,64]$ and anti-SCL-70 $[44,64]$ antibodies are not associated with survival.

Other potential prognostic factors remain controversial due to the presence of conflicting studies (table 4). P pa has been evaluated in three studies. MACGREGOR et al. [64] reported that at baseline systolic $P$ pa was associated with survival. They also reported that the association between an increasing $P$ pa and survival was suggestive, but not statistically significant. MUKERJEE et al. [40] reported survival differences in patients with $\bar{P}_{\text {pa }}<32 \mathrm{mmHg}, 32-44 \mathrm{mmHg}$ and $>45 \mathrm{mmHg}$. Yet recently, LAUNAY et al. [65] found no difference in survival in patients with a $\bar{P}_{\text {pa }} \leqslant 35 \mathrm{mmHg}$ versus $>35 \mathrm{mmHg}$. Differences in the measurement of $P$ pa (systolic versus mean), timing (baseline versus after treatment) and categorisation of $P$ pa may account for the differences in the study findings. The subtype of
SSc (limited versus diffuse) [64, 67], the presence of interstitial lung disease $[40,44,49,51]$ and duration of SSc prior to development of PAH $[44,55,68]$ are also controversial prognostic factors with conflicting studies.

There are several reasons for the discrepancies in the literature. The conduct and interpretation of prognostic studies of survival in SSc-PAH face a number of challenges. Frequently, factors appear to prognosticate survival in univariate analyses. However, the relationship does not remain in multivariate models. This can occur when potential factors are related, and represent facets of the same construct (e.g. haemodynamic parameters). Furthermore, the methodological quality of the SSc-PAH prognostic studies is variable. The attributes of participants, prognostic factors and outcome measures are well reported, whereas attributes of study attrition, confounding and the analytic methods used are not well reported [62]. These issues may introduce bias in the evaluation of effect. Finally, the small sample sizes may result in insufficient power to detect a true relationship. As such, further evaluation of prognostic factors in SSc-PAH in studies that meet the current rigours of measurement science is needed.

TABLE 3 Prognostic factors associated and not associated with systemic sclerosis-associated pulmonary arterial hypertension

Prognostic factor

\section{Factors associated with survival \\ HLA DRw6 \\ HLA DRW52 \\ Elevated mean Pra \\ Higher mixed venous oxygen saturation \\ PVR}

SVI

Pulmonary artery capacitance

Functional class

Sex

Age yrs

Estimated glomerular filtration rate ${ }^{\#}$

Signs of right heart failure

Factors not associated with survival

Anti-centromere antibody

Anti-Scl-70
Estimate

Ref.

RR $54.52(p=0.01)$

RR not reported $(p=0.02)$

HR $20.7(p=0.0001)$

HR 0.17, 95\% Cl 0.09-0.33

No difference in Kaplan-Meier curves in patients with a change in PVR $<20 \%, 20-34 \%$ or $\geqslant 35 \%(p=0.8)$

HR 1.10, 95\% Cl 1.03-1.18 $(\mathrm{p}<0.01)$

PVR index: HR 1.05, 95\% Cl 1.01-1.09 $(p<0.01)$

HR $1.20,95 \% \mathrm{Cl} 1.02-1.41(\mathrm{p}=0.02)$

HR $0.94,95 \% \mathrm{Cl} 0.89-0.99(p=0.02)$

HR $0.43,95 \% \mathrm{Cl} 0.20-0.91(p=0.03)$

Lower functional class has better survival:

HR 2.26, 95\% Cl 1.02-4.97

NYHA classes III/IV: HR 4.54, 95\% Cl 1.37-8.33 ( $p=0.01)$

WHO classes III/IV have worse survival than classes I/II:

log rank test $\mathrm{p}=0.02$

Males have worse survival: $\mathrm{HR} 2.02,95 \% \mathrm{Cl} 0.65-6.20^{\circ}$

Females have better survival: HR 2.20, 95\% Cl 1.36-3.55

[63]

[63]

[40]

[44]

[40]

[55]

[51]

[56]

[55]

[55]

[44]

[56]

[55]

Age $>50$ yrs has worse survival: HR 2.34, 95\% Cl 0.54-10.2

Younger age has better survival: $\mathrm{HR} 0.66,95 \% \mathrm{Cl} 0.34-1.29$

HR 2.63, 95\% Cl 1.29-5.37 $(\mathrm{p}<0.01)^{+}$

HR 2.56, 95\% Cl 1.02-14.28 $(p=0.04)$

[64]

[44]

[64]

[44]

[55]

[56]

HR 1.67, 95\% Cl 0.66-4.26

[64]

No effect on survival: data not reported

[44]

HR 0.28, 95\% Cl 0.03-1.99

[64]

No effect on survival: data not reported

f.

]

HLA: human leukocyte antigen; Pra: right atrial pressure; PVR: pulmonary vascular resistance; SVI: stroke volume index; NYHA: New York Heart Association; WHO: World Health Organization. ${ }^{\#}:<60 \mathrm{~mL} \cdot \mathrm{min}^{-1} \cdot 1.73 \mathrm{~m}^{-2}$; ${ }^{\bullet}$ : estimate was suggestive but not statistically significant; ${ }^{+}$: estimate from univariate analysis. Multivariate models including different haemodynamic parameters estimate HR 2.56-3.41. 


\begin{tabular}{|c|c|c|c|c|}
\hline TABLE 4 & \multicolumn{4}{|c|}{$\begin{array}{l}\text { Controversial prognostic factors for survival in systemic sclerosis (SSc)-associated pulmonary arterial hypertension } \\
\text { (PAH) }\end{array}$} \\
\hline \multicolumn{2}{|c|}{ Prognostic factor } & Estimate & Inference & Ref. \\
\hline \multirow{6}{*}{\multicolumn{2}{|c|}{ Ppa }} & Baseline systolic $P$ pa $>60 \mathrm{mmHg}$ : & Yes & [64] \\
\hline & & HR $3.60,95 \%$ Cl 1.42-9.15 & Suggestive but not significant & [64] \\
\hline & & Increasing Ppa: HR 5.36, 95\% Cl 0.4-37.8 & Yes & [40] \\
\hline & & 75,61 and $33 \%$, respectively & & \\
\hline & & (Kaplan-Meier estimate $\mathrm{p}<0.01)$ & & \\
\hline & & $\begin{aligned} \bar{P} \text { pa } \leqslant & 35 \mathrm{mmHg} \text { versus }>35 \mathrm{mmHg} \text { showed no difference } \\
& \text { (Kaplan-Meier estimate log rank test } \mathrm{p}=0.08 \text { ) }\end{aligned}$ & & \\
\hline \multirow{2}{*}{\multicolumn{2}{|c|}{ Limited sub-type }} & HR $2.37,95 \% \mathrm{Cl} 0.68-8.20$ & Suggestive but not significant & [64] \\
\hline & & $\begin{array}{l}\text { Limited and diffuse SSc have equally poor survival: } 10-20 \% \text { at } 5 \text { yrs } \\
\text { (test of significance not reported) }\end{array}$ & No & {$[67]$} \\
\hline \multirow{4}{*}{\multicolumn{2}{|c|}{ Interstitial lung disease }} & (95\% Cl 3-58 months) versus 11.5 months ( $95 \% \mathrm{Cl} 4-26$ months); log rank $\mathrm{p}=0.20$ & Yes & [51] \\
\hline & & 3 -yr survival $47 \%$ versus $28 \% ; p=0.005$ & Yes & [65] \\
\hline & & HR 5.15, 95\% Cl 1.73-15.3 $(p<0.01)$ & & \\
\hline & & 3-yr survival SSc-PH-ILD $47 \%$ versus SSc-PAH 71\% $(p=0.07)$ & & \\
\hline \multirow{3}{*}{\multicolumn{2}{|c|}{$\begin{array}{l}\text { Time between SSc onset and } \\
\text { observed PAH }\end{array}$}} & 5.24 versus 9.93 yrs $(p<0.01)$ & Yes & {$[68]$} \\
\hline & & HR 0.99 95\% Cl 0.95-1.03 $(p=0.60)$ & No & [55] \\
\hline & & Data not reported & No & [44] \\
\hline
\end{tabular}

Ppa: pulmonary artery pressure; $\bar{P}$ pa: mean pulmonary artery pressure; PH: pulmonary hypertension; ILD: interstitial lung disease.

Several studies of PAH-specific therapies have included SSc$\mathrm{PAH}$ patients, in addition to other forms of PAH (idiopathic PAH, SLE-PAH and repaired PAH) [69, 70]. Collectively, improvements in haemodynamics, time to clinical worsening and functional capacity have been demonstrated. However, investigators have demonstrated a treatment effect of lesser magnitude in SSc-PAH patients compared to idiopathic PAH patients [69, 70]. For example, RUBIN et al. [70] demonstrated an improvement in 6-min walk test (6MWT) distance in bosentan treated idiopathic PAH patients (increase of $46 \mathrm{~m}$ in bosentan group versus a decrease of $5 \mathrm{~m}$ in placebo group); whereas bosentan prevented deterioration in 6MWT distance in SSc$\mathrm{PAH}$ patients (increase of $3 \mathrm{~m}$ in the bosentan group versus a decrease of $40 \mathrm{~m}$ in the placebo group). Similarly, in a trial evaluating inhaled iloprost compared to placebo, OLSCHEWSKI et al. [69] demonstrated a 12-m improvement in 6MWT distance in the iloprost treated SSc-PAH patients compared to a 58.8-m improvement in the iloprost treated idiopathic $\mathrm{PAH}$ patients. The SSc-PAH patients, however, did achieve comparable improvements in the Mahler Dyspnoea Index and measures of quality of life as idiopathic PAH patients [69].

Randomised trials of PAH-specific therapies in SSc-PAH patients alone are limited. BADESCH et al. [58] reported a randomised, open-label trial comparing epoprostenol with conventional therapy versus conventional therapy alone in SSc-PAH patients. Using the $6 \mathrm{MWT}$ distance at 12 weeks as the primary outcome measure, they found a difference between treatment groups of $108 \mathrm{~m}(95 \%$ CI 55.2-180.0 m; p < 0.001). They also demonstrated a haemodynamic improvement in the treatment group. The change in $\bar{P}_{\mathrm{pa}}$ in the epoprostenol group and conventional treatment group were $-5.0 \mathrm{mmHg}$ and $0.9 \mathrm{mmHg}$, respectively (difference $-6.0 \mathrm{mmHg}, 95 \% \mathrm{CI}-9.0--3.0 \mathrm{mmHg}$ ). The mean changes in pulmonary vascular resistance were $-4.6 \mathrm{mmHg} \cdot \mathrm{L}^{-1} \cdot \mathrm{min}^{-1}$ and $0.9 \mathrm{mmHg} \cdot \mathrm{L}^{-1} \cdot \mathrm{min}^{-1}$ in the epoprostenol and conventional treatment groups, respectively (difference $-5.5 \mathrm{mmHg} \cdot \mathrm{L}^{-1} \cdot \mathrm{min}^{-1}$, $95 \%$ CI $\left.-7.3-3.7 \mathrm{mmHg} \cdot \mathrm{L}^{-1} \cdot \mathrm{min}^{-1}\right)$. There was no difference in survival between groups with four deaths in the treatment arm and five deaths in the control arm (p-value not significant) [58]. Using a comparison of natural history data [49], BADESCH et al. [71] reported improved long-term survival in the open-label extension study following the randomised trial. The probabilities of survival during the first and second year were 0.71 and 0.52 , respectively. The probability of survival remained constant at 0.48 during the third and fourth years [71].

There is no evidence that immunosuppressives are effective in SSc-PH. SANCHEZ et al. [72] reported six SSc-PAH patients treated with monthly intravenous cyclophosphamide for $\geqslant 3$ months with or without glucocorticoids. Response was defined as functional class I or II with sustained haemodynamic improvement after $\geqslant 1$ yr of immunosuppressive therapy without the addition of $\mathrm{PH}$-specific therapies. None of the patients achieved a response [72].

The 6MWT is a commonly used efficacy end-point in clinical trials including SSc-PH patients, and is a measure of exercise capacity accepted by the US Food and Drug Administration. However, evaluation of its psychometric properties for use as an outcome measure in SSc-PAH trials is limited. In patients with 
SSc-PAH, the 6MWT has concurrent validity. Improvements in 6MWT distance are associated with improvements in dyspnoea,

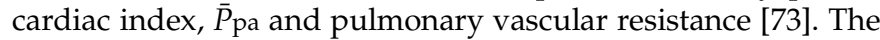
$6 \mathrm{MWT}$ has discriminant ability, differentiating patients receiving placebo and active treatment $(36 \mathrm{~m}$ improvement in epoprostenol arm versus $15 \mathrm{~m}$ decline in placebo arm; $75 \mathrm{~m}$ improvement sildenafil arm versus $0 \mathrm{~m}$ placebo arm) [58, 73]. The greatest threat to the utility of the 6MWT as an outcome measure is its face validity, i.e. does it measure what it purports to measure. The $6 \mathrm{MWT}$ is not only a test of cardiopulmonary function, but also a test of musculoskeletal function. As such, SSc-PAH patients may have limitation in 6MWT distance resulting from arthritis, myositis, myopathy, digital ulceration, claudication or gangrene [74]. Furthermore, pain (e.g. arthralgia or myalgia) can also limit 6MWT distance [74]. SSc patients with arthritis experience more pain than patients with rheumatoid arthritis [75]. These SSc manifestations may mask any improvements in cardiopulmonary function and confound the measure of treatment effect.

\section{SLE-ASSOCIATED PH}

$\mathrm{PH}$ is also a recognised manifestation of SLE. Prevalence estimates range from $0.005 \%$ to $14 \%$ [1, 76-84]. The wide range in prevalence estimates may be due to several factors. Early prevalence studies relied on detection of clinical symptoms. It was previously felt that routine screening of SLE patients was not justified due to the lack of effective therapy [85]. Furthermore, the accuracy of prevalence estimates was affected by the use of different diagnostic cut-offs for the diagnosis of PAH. The threshold of $P$ pa required for a diagnosis of PH in SLE was frequently higher than that used for SSc. In particular, the cut-off for the catheterisation-based diagnosis was high in the reported studies, e.g. $\bar{P}_{\text {pa }}>30 \mathrm{mmHg}$ as opposed to a conventional cut-off of $>25 \mathrm{mmHg}$ (table 5). Therefore, although SLE-PH is less frequent than SSc-PAH, PAH may be an under-recognised manifestation of SLE [3].

The diagnosis of SLE frequently occurs before the diagnosis of PAH, with a mean delay of 4.9 yrs ( $\pm 3.7 \mathrm{yrs}$ ) [87]. The development of PAH in the setting of SLE has been associated with antiribonucleoprotein antibodies [88], the presence of Raynaud's phenomenon [1, 78, 72,83], rheumatoid factor positivity [76, 82] and elevated levels of endothelin-1 [82]. More recently, FoIs et al. [85] reported that a systolic $P$ pa $\geqslant 35 \mathrm{mmHg}$ was more common in subjects of African descent (50\% versus $20 \%$; $p=0.03$ ); with longer disease duration ( $14 \pm 8$ versus $9.5 \pm 8$ yrs; $\mathrm{p}=0.049)$; with a history of peripheral nervous system involvement ( $25 \%$ versus $4 \% ; \mathrm{p}=0.02)$; with pericarditis ( $58 \%$ versus $27 \% ; \mathrm{p}=0.04)$; and with anti-smooth muscle antibodies ( $42 \%$ versus $11 \% ; \mathrm{p}=0.01)$ and anticardiolipin antibodies (75\% versus $31 \% ; \mathrm{p}=0.007)$.

There are fewer data evaluating survival in SLE-PAH than SSc$\mathrm{PAH}$. Some estimates suggest a poor prognosis with a median survival of 13 months [77]; however, more recent survival estimates are more optimistic (table 6) $[5,57]$. SLE-PAH patients have a shorter time from diagnosis to death compared to idiopathic PAH patients, with a reported hazard ratio of 2.6 (95\% CI 1.1-6.1) [76]. PAH was the third most common cause of death in Korean SLE patients [89]. PAH has been reported as a common cause of death in Chinese and Korean patients, but not a common cause of death in North American or European cohorts [3], suggesting that ethnicity or access to care may be

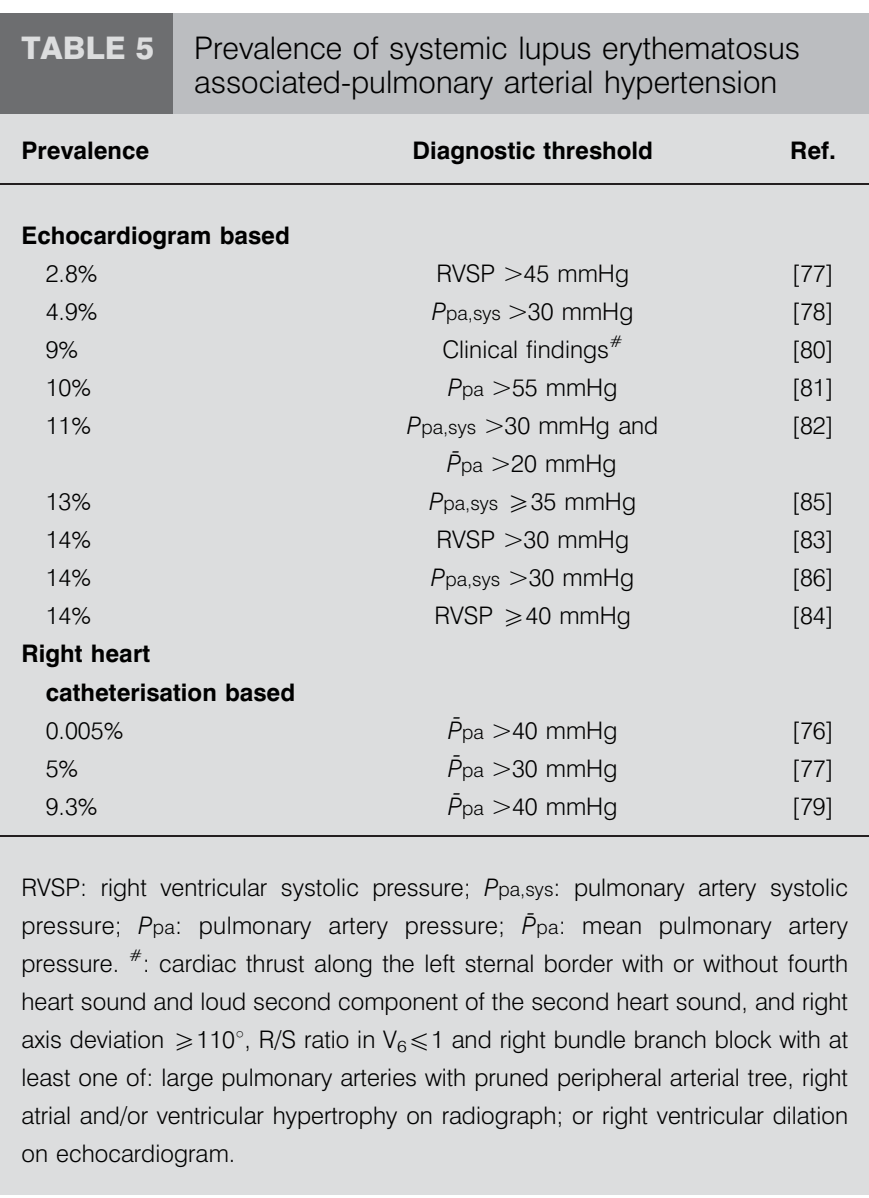

prognostic factors for survival. Our recent systematic review of the literature [90] identified a number of clinical factors that may be associated with survival; magnitude of the elevation in $\bar{P}_{\text {pa }}$ at diagnosis $[78,89,91]$, thrombosis $[89,92,93]$, thrombocytopenia [94], presence of an anti-cardiolipin antibody [89, 92, 93], concurrent pregnancy [95, 96], infection [77], Raynaud's phenomenon [93, 97], plexiform lesion [95] and pulmonary vasculitis [96]. Conversely, lupus central nervous system disease [89], lupus nephritis [89] and lupus disease activity [89, 98-100] have not been associated with survival in SLE-PH. It has been suggested that SLE-PAH patients have a better prognosis than SSc-PAH patients, where CONDLIFFE et al. [44] reported a 3-yr survival rate of $75 \%$ in SLE-PAH compared to $47 \%$ in SSc-PA patients in the UK $(\mathrm{p}=0.01)$.

The role of immunosuppressive therapy in SLE-PH is controversial. Several small case reports/series have reported improvement with immunosuppressive therapy [87, 101-103]. However, others have reported clinical deterioration in SLE-PH despite immunosuppressive therapy $[99,104]$. Recent observational studies suggest that a subset of SLE-PH patients will improve with immunosuppression. SANCHEZ et al. [72] report that five $(38 \%)$ out of 13 SLE-PH patients treated with monthly intravenous cyclophosphamide $600 \mathrm{mg} \cdot \mathrm{m}^{-2}$ with or without glucocorticoids remained in New York Heart Association (NYHA) functional class I or II with sustained haemodynamic improvement after $1 \mathrm{yr}$ of therapy. The same group later reported similar findings with four (44\%) out of nine SLE-PH patients treated with monthly intravenous cyclophosphamide 
TABLE 6 Survival in systemic lupus erythematosus associated-pulmonary arterial hypertension

\begin{tabular}{|c|c|c|c|c|c|}
\hline \multicolumn{5}{|c|}{ Survival \% } & \multirow[t]{2}{*}{ Ref. } \\
\hline $1-y r$ & $2-y r$ & 3-yr & $5-y r$ & Median & \\
\hline Not reported & Not reported & Not reported & 50 & $5 \mathrm{yrs}$ & [1] \\
\hline Not reported & Not reported & Not reported & 86 & Not reported & [86] \\
\hline 50.5 & Not reported & 44.9 & 16.8 & 13 months & [77] \\
\hline 100 & 95.1 & 87.2 & 87.2 & Not reported & [6] \\
\hline 78 & Not reported & 74 & Not reported & Not reported & [45] \\
\hline 94 & Not reported & Not reported & Not reported & Not reported & [57] \\
\hline
\end{tabular}

and glucocorticoids remaining in NYHA functional class I or II with a $\bar{P}_{\mathrm{pa}}<40 \mathrm{mmHg}$ and/or a normal cardiac index [5]. It has also been observed that some SLE-PH patients can be transitioned from parental prostaglandin therapy to oral $\mathrm{PH}$-specific treatment with continued improvement [105]. These outcomes contrast with SSc-PAH where, in general, immunosuppressive therapy is not effective and often requires the escalation of $\mathrm{PH}$ specific therapy [72].

Together, these findings suggest PH in the setting of SLE may not represent one homogenous condition, but may reflect the final common pathway in a few distinct pathologically based subsets $[3,106]$. One subset may be those prone to thromboembolic disease. Features of this subset include the presence of the anti-phospholipid antibody syndrome, lupus anticoagulant/ anti-cardiolipin antibodies [1] (note that the relationship between $\mathrm{PH}$ and the lupus anticoagulant is not reproducible [107]), increased risk of developing thrombotic arteriopathy and pulmonary embolism [88]. This subset of patients may benefit from concurrent anticoagulation. A second subset may be those with a pulmonary vasculopathy similar to SSc-PAH. This vasculopathy manifests as noninflammatory vascular remodelling, may contain the plexiform lesion and may be associated with the anti-ribonucleoprotein antibody. A third pathological based subset is one with an immune-mediated vasculopathy leading to pulmonary vasculitis: inflammation of the pulmonary artery that may be reversible with immunosuppression [106]. Indeed, some patients with SLE-PAH have been found to have circulating anti-endothelial cell antibodies [108]. This suggests B-cell activation may be part of the pathogenesis of SLE-PAH. Consequently, suppression of these antibodies may represent another rationale for concurrent immunosuppressive therapy. Similarly, immune complex deposition (large amounts of immunoglobulin (Ig)G and C1q, and small amounts of IgM and C3 in the intimal and medial layers) has been described in the pulmonary vessels of SLE-PH patients, again supporting a role for immunosuppression [76]. This inflammatory or "vasculitic" SLE-PAH subset classification is hypothesis generating and requires formal validation. If correct, this may explain why there has been a differential response to immunosuppressive therapy in observational studies [5, 72]. Correct identification of subsets may facilitate appropriate targeted therapy, allow treatment to start before irreversible vascular lesions occur [109] and identify those patients who can be stepped down to less aggressive therapy [110].
Clinical studies of PAH-specific therapy often include SSc$\mathrm{PAH}$ and SLE-PAH under the all-encompassing category of CTD. DENTON et al. [15] reported the effect of bosentan at 48 weeks in $42 \mathrm{SSc}-\mathrm{PH}$, five SLE-PAH patients and six MCTD patients. Functional class improved in $27 \%$ (95\% CI 16-42\%) and worsened in $16 \%$ (95\% CI 7-29\%) of patients. The KaplanMeier estimate for survival at 48 weeks was $92 \%$ (95\% CI 85$100 \%$ ) [15]. A post hoc, subgroup analysis of the SUPER-1 trial (12-week, double-blind evaluation of sildenafil 20, 40 or $80 \mathrm{mg}$ t.i.d. or placebo) evaluated outcomes in 38 SSc-PAH, 19 SLE$\mathrm{PAH}$ and 17 patients with other CTDs. Sildenafil-treated patients demonstrated mean increases in 6-min walk distance of $42 \mathrm{~m}$ (95\% CI 20-64 m), $36 \mathrm{~m}$ (95\% CI 14-58 m) and $15 \mathrm{~m} \mathrm{(95 \%}$ CI $-24-54 \mathrm{~m})$ for 20,40 and $80 \mathrm{mg}$, respectively, and a mean decrease of $13 \mathrm{~m}(95 \% \mathrm{CI}-36-10 \mathrm{~m})$ in the placebo group. Improvement of at least one functional class occurred in 29$42 \%$ of the sildenafil-treated patients compared to $5 \%$ of placebo-treated patients [14].

A few additional issues should be taken into consideration in the management of patients with SLE-PH. First, the use of a central venous line for epoprostenol infusion is associated with catheter infection and/or sepsis. In SLE-PAH patients treated with immunosuppressants, the risk of infection may be greater and, thus, may influence the treatment decision. Secondly, there is a risk of severe thrombocytopenia with epoprostenol in SLE-PAH. This may be of particular concern when thrombocytopenia precedes the start of epoprostenol therapy [111].

\section{CONCLUSION}

Our understanding of the epidemiology of SSc-PAH has improved with increased precision in prevalence estimates and identification of prognostic factors. Short-term survival in SSc$\mathrm{PAH}$ has improved with the introduction of $\mathrm{PAH}$-specific therapies. However, long-term survival $(\geqslant 5 \mathrm{yr})$ remains discouraging, leaving room for newer advances in the understanding of pathophysiology and treatment. SLE-PAH is relatively under studied compared to SSc-PAH, and requires well-designed, appropriately powered studies. The current data suggests there are subsets of SLE-PH patients with a worse prognosis than SSc-PAH patients; however, there is also a subset of SLE-PAH patients who will respond to concomitant immunosuppressive therapy resulting in normalisation of cardiopulmonary haemodynamics. Research into these findings will undoubtedly lead to further refinement in our understanding of $\mathrm{PH}$ in the CTDs. 


\section{SUPPORT STATEMENT}

S.R. Johnson is supported by a Canadian Institutes of Health Research Clinician Scientist Award and the Norton-Evans Fund for Scleroderma Research.

\section{STATEMENT OF INTEREST}

J.T. Granton has received funding to support research from Pfizer and Actelion. He has also acted as an expert witness for Pfizer and consultant for Actelion, Pfizer, Lilly and GlaxoSmithKline. He has received honoraria for speaking from Lilly, Pfizer and Actelion.

\section{REFERENCES}

1 Asherson RA, Higenbottam TW, Dinh Xuan AT, et al. Pulmonary hypertension in a lupus clinic: experience with twenty-four patients. J Rheumatol 1990; 17: 1292-1298.

2 Tanaka E, Harigai M, Tanaka M, et al. Pulmonary hypertension in systemic lupus erythematosus: evaluation of clinical characteristics and response to immunosuppressive treatment. J Rheumatol 2002; 29: 282-287.

3 Pope J. An update in pulmonary hypertension in systemic lupus erythematosus - do we need to know about it? Lupus 2008; 17 : 274-277.

4 Dahl M, Chalmers A, Wade J, et al. Ten year survival of a patient with advanced pulmonary hypertension and mixed connective tissue disease treated with immunosuppressive therapy. J Rheumatol 1992; 19: 1807-1809.

5 Jais X, Launay D, Yaici A, et al. Immunosuppressive therapy in lupus- and mixed connective tissue disease-associated pulmonary arterial hypertension: a retrospective analysis of twentythree cases. Arthritis Rheum 2008; 58: 521-531.

6 Burdt MA, Hoffman RW, Deutscher SL, et al. Long-term outcome in mixed connective tissue disease: longitudinal clinical and serologic findings. Arthritis Rheum 1999; 42: 899-909.

7 Bunch TW, Tancredi RG, Lie JT. Pulmonary hypertension in polymyositis. Chest, 1981; 79: 105-107.

8 Minai OA. Pulmonary hypertension in polymyositis-dermatomyositis: clinical and hemodynamic characteristics and response to vasoactive therapy. Lupus 2009; 18: 1006-1010.

9 Launay D, Hachulla E, Hatron PY, et al. Pulmonary arterial hypertension: a rare complication of primary Sjogren syndrome: report of 9 new cases and review of the literature. Medicine (Baltimore) 2007; 86: 299-315.

10 Dawson JK, Goodson NG, Graham DR, et al. Raised pulmonary artery pressures measured with Doppler echocardiography in rheumatoid arthritis patients. Rheumatology (Oxford) 2000; 39: 1320-1325.

11 Badesch DB, Champion HC, Sanchez MA, et al. Diagnosis and assessment of pulmonary arterial hypertension. J Am Coll Cardiol 2009; 54: Suppl. 1, S55-S66.

12 Galie N, Hoeper MM, Humbert M, et al. Guidelines for the diagnosis and treatment of pulmonary hypertension. Eur Respir J 2009; 34: 1219-1263.

13 Humbert M, Sitbon O, Chaouat A, et al. Pulmonary arterial hypertension in France: results from a national registry. Am J Respir Crit Care Med 2006; 173: 1023-1030.

14 Badesch DB, Hill NS, Burgess G, et al. Sildenafil for pulmonary arterial hypertension associated with connective tissue disease. J Rheumatol 2007; 34: 2417-2422.

15 Denton CP, Pope JE, Peter HH, et al. Long-term effects of bosentan on quality of life, survival, safety and tolerability in pulmonary arterial hypertension related to connective tissue diseases. Ann Rheum Dis 2008; 67: 1222-1228.

16 Keogh A, Strange G, Kotlyar E, et al. Survival after the initiation of combination therapy in patients with pulmonary arterial hypertension: an Australian collaborative report. Intern Med J 2011; 41: 235-244.

17 Johnson SR, Patsios D, Hwang DM, et al. Pulmonary venoocclusive disease and scleroderma associated pulmonary hypertension. J Rheumatol 2006; 33: 2347-2350.

18 de Groote P, Gressin V, Hachulla E, et al. Evaluation of cardiac abnormalities by Doppler echocardiography in a large nationwide multicentric cohort of patients with systemic sclerosis. Ann Rheum Dis 2008; 67: 31-36.

19 Launay D, Mouthon L, Hachulla E, et al. Prevalence and characteristics of moderate to severe pulmonary hypertension in systemic sclerosis with and without interstitial lung disease. J Rheumatol 2007; 34: 1005-1011.

20 Dorfmuller P, Humbert M, Perros F, et al. Fibrous remodeling of the pulmonary venous system in pulmonary arterial hypertension associated with connective tissue diseases. Hum Pathol 2007; 38: 893-902.

21 Dorfmuller P, Montani D, Humbert M. Beyond arterial remodelling: pulmonary venous and cardiac involvement in patients with systemic sclerosis-associated pulmonary arterial hypertension. Eur Respir J 2010; 35: 6-8.

22 Varga J, Whitfield ML. Transforming growth factor-beta in systemic sclerosis (scleroderma). Front Biosci (Schol Ed) 2009; 1 226-235.

23 Strange G, Nash P. The manifestations of vasculopathy in systemic sclerosis and its evidence-based therapy. Int J Rheum Dis 2009; 12: 192-206.

24 Walker JG, Stirling J, Beroukas D, et al. Histopathological and ultrastructural features of dermal telangiectasias in systemic sclerosis. Pathology 2005; 37: 220-225.

25 Fujimoto M, Hasegawa M, Hamaguchi $Y$, et al. A clue for telangiectasis in systemic sclerosis: elevated serum soluble endoglin levels in patients with the limited cutaneous form of the disease. Dermatology 2006; 213: 88-92.

26 Shah AA, Wigley FM, Hummers LK. Telangiectases in scleroderma: a potential clinical marker of pulmonary arterial hypertension. J Rheumatol 2010; 37: 98-104.

27 Duchini A, Sessoms SL. Gastrointestinal hemorrhage in patients with systemic sclerosis and CREST syndrome. Am J Gastroenterol 1998; 93: 1453-1456.

28 Johnson SR, Omair M. Gastric antral vascular ectasia unmasked by alprostadil for digital ulceration in scleroderma. J Rheumatol 2011; 38: 784-785.

29 Preliminary criteria for the classification of systemic sclerosis (scleroderma). Subcommittee for scleroderma criteria of the American Rheumatism Association Diagnostic and Therapeutic Criteria Committee. Arthritis Rheum 1980; 23: 581-590.

30 Hudson M, Taillefer S, Steele R, et al. Improving the sensitivity of the American College of Rheumatology classification criteria for systemic sclerosis. Clin Exp Rheumatol 2007; 25: 754-757.

31 Hochberg MC. Updating the American College of Rheumatology revised criteria for the classification of systemic lupus erythematosus. Arthritis Rheum 1997; 40: 1725.

32 Johnson SR, Goek ON, Singh-Grewal D, et al. Classification criteria in rheumatic diseases: a review of methodologic properties. Arthritis Rheum 2007; 57: 1119-1133.

33 Fransen F, Johnson SR, Tyndall A, et al. Results of the Delphi for EULAR/ACR Classification Criteria Working Group in Systemic Sclerosis. Arthritis Rheum 2010; 62: S921-S922.

34 Murata I, Kihara H, Shinohara S, et al. Echocardiographic evaluation of pulmonary arterial hypertension in patients with progressive systemic sclerosis and related syndromes. Jpn Circ J 1992; 56: 983-991.

35 Murata I, Takenaka K, Yoshinoya S, et al. Clinical evaluation of pulmonary hypertension in systemic sclerosis and related disorders. A Doppler echocardiographic study of 135 Japanese patients. Chest 1997; 111: 36-43. 
36 Pope JE, Lee P, Baron M, et al. Prevalence of elevated pulmonary arterial pressures measured by echocardiography in a multicenter study of patients with systemic sclerosis. J Rheumatol 2005; 32: 1273-1278.

37 Wigley FM, Lima JA, Mayes M, et al. The prevalence of undiagnosed pulmonary arterial hypertension in subjects with connective tissue disease at the secondary health care level of community-based rheumatologists (the UNCOVER study). Arthritis Rheum 2005; 52: 2125-2132.

38 Salerni R, Rodnan GP, Leon DF, et al. Pulmonary hypertension in the CREST syndrome variant of progressive systemic sclerosis (scleroderma). Ann Intern Med 1977; 86: 394-399.

39 Ungerer RG, Tashkin DP, Furst D, et al. Prevalence and clinical correlates of pulmonary arterial hypertension in progressive systemic sclerosis. Am J Med 1983; 75: 65-74.

40 Mukerjee D, St George D, Coleiro B, et al. Prevalence and outcome in systemic sclerosis associated pulmonary arterial hypertension: application of a registry approach. Ann Rheum Dis 2003; 62: 1088-1093.

41 Hachulla E, Gressin V, Guillevin L, et al. Early detection of pulmonary arterial hypertension in systemic sclerosis: a French nationwide prospective multicenter study. Arthritis Rheum 2005; 52: 3792-3800.

42 Battle RW, Davitt MA, Cooper SM, et al. Prevalence of pulmonary hypertension in limited and diffuse scleroderma. Chest 1996; 110: 1515-1519.

43 Yamane $\mathrm{K}$, Ihn H, Asano Y, et al. Clinical and laboratory features of scleroderma patients with pulmonary hypertension. Rheumatology (Oxford) 2000; 39: 1269-1271.

44 Condliffe R, Kiely DG, Peacock AJ, et al. Connective tissue disease-associated pulmonary arterial hypertension in the modern treatment era. Am J Respir Crit Care Med 2009; 179: 151-157.

45 Avouac J, Airo P, Meune C, et al. Prevalence of pulmonary hypertension in systemic sclerosis in European Caucasians and metaanalysis of 5 studies. J Rheumatol 2010; 37: 2290-2298.

46 Fisher MR, Mathai SC, Champion HC, et al. Clinical differences between idiopathic and scleroderma-related pulmonary hypertension. Arthritis Rheum 2006; 54: 3043-3050.

47 Hachulla E, Launay D, Mouthon L, et al. Is pulmonary arterial hypertension really a late complication of systemic sclerosis? Chest 2009; 136: 1211-1219.

48 Steen VD, Medsger TA. Changes in causes of death in systemic sclerosis, 1972-2002. Ann Rheum Dis 2007; 66: 940-944.

49 Koh ET, Lee P, Gladman DD, et al. Pulmonary hypertension in systemic sclerosis: an analysis of 17 patients. Br J Rheumatol 1996; 35: 989-993.

50 Johnson SR, Granton JT, Tomlinson GA, et al. Warfarin in scleroderma-associated and idiopathic pulmonary arterial hypertension. A Bayesian approach to evaluating disease in uncommon disease. J Rheumatol 2011; (In press).

51 Mathai SC, Hummers LK, Champion HC, et al. Survival in pulmonary hypertension associated with the scleroderma spectrum of diseases: impact of interstitial lung disease. Arthritis Rheum 2009; 60: 569-577.

52 Stupi AM, Steen VD, Owens GR, et al. Pulmonary hypertension in the CREST syndrome variant of systemic sclerosis. Arthritis Rheum 1986; 29: 515-524.

53 Steen V, Medsger TA Jr. Predictors of isolated pulmonary hypertension in patients with systemic sclerosis and limited cutaneous involvement. Arthritis Rheum 2003; 48: 516-522.

54 Williams MH, Das C, Handler CE, et al. Systemic sclerosis associated pulmonary hypertension: improved survival in the current era. Heart 2006; 92: 926-932.

55 Campo A, Mathai SC, Le Pavec J, et al. Hemodynamic predictors of survival in scleroderma-related pulmonary arterial hypertension. Am J Respir Crit Care Med 2010; 182: 252-260.
56 Launay D, Sitbon O, Le Pavec J, et al. Long-term outcome of systemic sclerosis-associated pulmonary arterial hypertension treated with bosentan as first-line monotherapy followed or not by the addition of prostanoids or sildenafil. Rheumatology (Oxford) 2010; 49: 490-500.

57 Chung L, Liu J, Parsons L, et al. Characterization of connective tissue disease-associated pulmonary arterial hypertension from REVEAL: identifying systemic sclerosis as a unique phenotype. Chest 2010; 138: 1383-1394.

58 Badesch DB, Tapson VF, McGoon MD, et al. Continuous intravenous epoprostenol for pulmonary hypertension due to the scleroderma spectrum of disease. A randomized, controlled trial. Ann Intern Med 2000; 132: 425-434.

59 Denton CP, Humbert M, Rubin L, et al. Bosentan treatment for pulmonary arterial hypertension related to connective tissue disease: a subgroup analysis of the pivotal clinical trials and their open-label extensions. Ann Rheum Dis 2006; 65: 1336-1340.

60 Galie N, Ghofrani HA, Torbicki A, et al. Sildenafil citrate therapy for pulmonary arterial hypertension. $N$ Engl J Med 2005; 353: $2148-2157$.

61 Benza RL, Miller DP, Gomberg-Maitland M, et al. Predicting survival in pulmonary arterial hypertension: insights from the Registry to Evaluate Early and Long-Term Pulmonary Arterial Hypertension Disease Management (REVEAL). Circulation 2010; 122: 164-172.

62 Johnson SR, Swiston JR, Granton JT. Prognostic factors for survival in scleroderma associated pulmonary arterial hypertension. J Rheumatol 2008; 35: 1584-1590.

63 Langevitz P, Buskila D, Gladman DD, et al. HLA alleles in systemic sclerosis: association with pulmonary hypertension and outcome. Br J Rheumatol 1992; 31: 609-613.

64 MacGregor AJ, Canavan R, Knight C, et al. Pulmonary hypertension in systemic sclerosis: risk factors for progression and consequences for survival. Rheumatology (Oxford) 2001; 40: 453-459.

65 Launay D, Humbert M, Berezne A, et al. Clinical characteristics and survival in systemic sclerosis-related $\mathrm{PH}$ associated with ILD. Chest 2011; [Epub ahead of print DOI 10.1378/chest.102473a].

66 Swiston JR, Johnson SR, Granton JT. Factors that prognosticate mortality in idiopathic pulmonary arterial hypertension: a systematic review of the literature. Respir Med 2010; 104: 1588-1607.

67 Sacks DG, Okano Y, Steen VD, et al. Isolated pulmonary hypertension in systemic sclerosis with diffuse cutaneous involvement: association with serum anti-U3RNP antibody. J Rheumatol 1996; 23: 639-642.

68 Kasukawa R, Nishimaki T, Takagi T, et al. Pulmonary hypertension in connective tissue disease. Clinical analysis of sixty patients in multi-institutional study. Clin Rheumatol 1990; 9: 56-62.

69 Olschewski H, Simonneau G, Galie N, et al. Inhaled iloprost for severe pulmonary hypertension. N Engl J Med 2002; 347: 322-329.

70 Rubin LJ, Badesch DB, Barst RJ, et al. Bosentan therapy for pulmonary arterial hypertension. N Engl J Med 2002; 346: 896-903.

71 Badesch DB, McGoon MD, Barst RJ, et al. Longterm survival among patients with scleroderma-associated pulmonary arterial hypertension treated with intravenous epoprostenol. J Rheumatol 2009; 36: 2244-2249.

72 Sanchez O, Sitbon O, Jais X, et al. Immunosuppressive therapy in connective tissue diseases-associated pulmonary arterial hypertension. Chest 2006; 130: 182-189.

73 Furst D, Khanna D, Matucci-Cerinic M, et al. Systemic sclerosis continuing progress in developing clinical measures of response. J Rheumatol 2007; 34: 1194-1200.

74 Garin MC, Highland KB, Silver RM, et al. Limitations to the 6minute walk test in interstitial lung disease and pulmonary hypertension in scleroderma. J Rheumatol 2009; 36: 330-336. 
75 Johnson SR, Glaman DD, Schentag CT, et al. Quality of life and functional status in systemic sclerosis compared to other rheumatic diseases. J Rheumatol 2006; 33: 1117-1122.

76 Quismorio FP Jr, Sharma O, Koss M, et al. Immunopathologic and clinical studies in pulmonary hypertension associated with systemic lupus erythematosus. Semin Arthritis Rheum 1984; 13: 349-359.

77 Chung SM, Lee CK, Lee EY, et al. Clinical aspects of pulmonary hypertension in patients with systemic lupus erythematosus and in patients with idiopathic pulmonary arterial hypertension. Clin Rheumatol 2006; 25: 866-872.

78 Li EK, Tam LS. Pulmonary hypertension in systemic lupus erythematosus: clinical association and survival in 18 patients. $J$ Rheumatol 1999; 26: 1923-1929.

79 Perez HD, Kramer N. Pulmonary hypertension in systemic lupus erythematosus: report of four cases and review of the literature. Semin Arthritis Rheum 1981; 11: 177-181.

80 Badui E, Garcia-Rubi D, Robles E, et al. Cardiovascular manifestations in systemic lupus erythematosus. Prospective study of 100 patients. Angiology 1985; 36: 431-441.

81 Ong ML, Veerapen K, Chambers JB, et al. Cardiac abnormalities in systemic lupus erythematosus: prevalence and relationship to disease activity. Int J Cardiol 1992; 34: 69-74.

82 Shen JY, Chen SL, Wu YX, et al. Pulmonary hypertension in systemic lupus erythematosus. Rheumatol Int 1999; 18: 147-151.

83 Simonson JS, Schiller NB, Petri M, et al. Pulmonary hypertension in systemic lupus erythematosus. J Rheumatol 1989; 16: 918-925.

84 Johnson SR, Gladman DD, Urowitz MB, et al. Pulmonary hypertension in systemic lupus. Lupus 2004; 13: 506-509.

85 Fois E, Le Guern V, Dupuy A, et al. Noninvasive assessment of systolic pulmonary artery pressure in systemic lupus erythematosus: retrospective analysis of 93 patients. Clin Exp Rheumatol 2010; 28: 836-841.

86 Winslow TM, Ossipov MA, Fazio GP, et al. Five-year follow-up study of the prevalence and progression of pulmonary hypertension in systemic lupus erythematosus. Am Heart J 1995; 129: 510-515.

87 Goupille P, Fauchier L, Babuty D, et al. Precapillary pulmonary hypertension dramatically improved with high doses of corticosteroids during systemic lupus erythematosus. J Rheumatol 1994; 21: 1976-1977.

88 Asherson RA, Hackett D, Gharavi AE, et al. Pulmonary hypertension in systemic lupus erythematosus: a report of three cases. J Rheumatol 1986; 13: 416-420.

89 Kim WU, Min JK, Lee SH, et al. Causes of death in Korean patients with systemic lupus erythematosus: a single center retrospective study. Clin Exp Rheumatol 1999; 17: 539-545.

90 Chow SL, Chandran V, Fazelzad R, et al. Prognostic factors for survival in systemic lupus erythematosus associated pulmonary hypertension. Lupus 2011; (In press).

91 Chen $\mathrm{CH}$, Chen HA, Wang HP, et al. Pulmonary arterial hypertension in autoimmune diseases: an analysis of 19 cases from a medical center in northern Taiwan. J Microbiol Immunol Infect 2006; 39: 162-168.

92 Semeniuk GB, Re R, Freue RD. Trombosis de grandes vasos pulmonares como causa de hipertension pulmonar severa en el lupus eritematoso sistémico [Thrombosis of great pulmonary vessels causing severe pulmonary hypertension in systemic lupus erythematosus]. Medicina (B Aires) 2001; 61: 319-321.
93 Bautista GG, Cabral A, Achurra AF. Hipertension pulmonar en el lupus eritematoso generalizado [Pulmonary hypertension in generalized lupus erythematosus]. Rev Med Panama 1992; 17: 23-27.

94 Robbins IM, Gaine SP, Schilz R, et al. Epoprostenol for treatment of pulmonary hypertension in patients with systemic lupus erythematosus. Chest 2000; 117: 14-18.

95 McMillan E, Martin WL, Waugh J, et al. Management of pregnancy in women with pulmonary hypertension secondary to SLE and anti-phospholipid syndrome. Lupus 2002; 11: 392-398.

96 Rubin LA, Geran A, Rose TH, et al. A fatal pulmonary complication of lupus in pregnancy. Arthritis Rheum 1995; 38: 710-714.

97 Lavras Costallat LT, Valente Coimbra AM. Raynaud's phenomenon in systemic lupus erythematosus. Rev Rhum Engl Ed 1995; 62: 349-353.

98 Kawamura N, Tsutsui H, Fukuyama K, et al. Severe pulmonary hypertension in a patient with systemic lupus erythematosus and minimal lupus activity. Intern Med 2002; 41: 109-112.

99 Koyama S, Ichiyoshi T, Chino M, et al. Systemic lupus erythematosus with pulmonary hypertension. Intern Med 1996; 35: 39-42.

100 Matsumoto N, Yamada A, Harada S, et al. [A case of lupus erythematosus preceded by right heart failure due to pulmonary hypertension]. Kokyu To Junkan 1991; 39: 1037-1041.

101 Kawaguchi Y, Hara M, Harigai M, et al. Corticosteroid pulse therapy in a patient with SLE and pulmonary hypertension. Clin Exp Rheumatol 1998; 16: 510.

102 Karmochkine M, Wechsler B, Godeau P, et al. Improvement of severe pulmonary hypertension in a patient with SLE. Ann Rheum Dis 1996; 55: 561-562.

103 Groen H, Bootsma H, Postma DS, et al. Primary pulmonary hypertension in a patient with systemic lupus erythematosus: partial improvement with cyclophosphamide. J Rheumatol 1993; 20: 1055-1057.

104 Turner A, Samanta A, Nichol FE. Primary pulmonary hypertension associated with systemic lupus erythematosus. Clin Rheumatol 1991; 10: 320-322.

105 Minai O. An update in pulmonary hypertension in systemic lupus erythematosus - do we need to know about it? Lupus 2009; 18: 92.

106 Asherson RA, Oakley CM. Pulmonary hypertension and systemic lupus erythematosus. J Rheumatol 1986; 13: 1-5.

107 Petri M, Rheinschmidt M, Whiting-O'Keefe $Q$, et al. The frequency of lupus anticoagulant in systemic lupus erythematosus. A study of sixty consecutive patients by activated partial thromboplastin time, Russell viper venom time, and anticardiolipin antibody level. Ann Intern Med 1987; 106: 524-531.

108 Yoshio T, Masuyama J, Mimori A, et al. Endothelin-1 release from cultured endothelial cells induced by sera from patients with systemic lupus erythematosus. Ann Rheum Dis 1995; 54: 361-365.

109 Haas C. L'hypertension artérielle pulmonaire associée au lupus érythémateux disséminé [Pulmonary hypertension associated with systemic lupus erythematosus]. Bull Acad Natl Med 2004; 188: 985-997.

110 Heresi GA, Minai OA. Lupus-associated pulmonary hypertension: long-term response to vasoactive therapy. Respir Med 2007; 101: 2099-2107.

111 Horn EM, Barst RJ, Poon M. Epoprostenol for treatment of pulmonary hypertension in patients with systemoc lupus erythematosus. Chest 200, 118: 1229-1230. 